\title{
NEW CONCEPT OF A ROCKER ENGINE - KINEMATIC ANALYSIS
}

\author{
Mirosław Szymkowiak \\ Kochanowskiego Street 13, 64-100 Leszno, Poland \\ e-mail:szymkowiak@op.pl \\ Stanislaw Szwaja \\ Czestochowa University of Technology, Institute of Thermal Machinery \\ Dabrowskiego Street 69, 42-200 Czestochowa, Poland \\ tel.: +4834350555, fax: +48343250555 \\ e-mail:szwaja@imc.pcz.czest.pl
}

\begin{abstract}
The paper presents concept and design of a four-stroke 4-cylinder internal combustion engine consisted of a single connecting rod to a crankshaft and four additional rods joining pistons with a rocker. The rocker is a specific element in the engine construction that makes this engine different from the typical reciprocating internal combustion piston engine. Furthermore, kinematical analysis of this piston-rocker-crankshaft mechanism was conducted. As concluded from the analysis, this mechanism implemented to the engine, provides several advantages with respect to both dynamic and thermodynamic related issues. First of all, a profile of the piston motion can be easily changed with change in the mechanism geometry e.g. major dimensions of connecting rods, the rocker etc. Thus, the piston motion profile can be asymmetrical with slow motion to and relatively fast distancing from the TDC. This feature can be useful in reducing thermal losses to an engine cooling system. Additionally, the mechanism characterizes itself with low transverse force from the piston, which acts on a cylinder liner. As a result, it significantly reduces frictional losses and should increase the overall efficiency of the engine. Among disadvantages, higher inertial forces are the most important problem. As analyzed, the rocker is the main component that contributes to increase in inertial forces by approximately three to four times. On the other hand, total inertia forces, due to specific kinematical chain of the mechanism, can be remarkably reduced in case the mechanism is correctly optimized.
\end{abstract}

Keywords: rocker, engine, kinematics, piston motion

\section{Introduction}

Investigation on improving the overall efficiency of the classic reciprocating engine has been conducted over years. Undertaken measures have been focused on combustion related issues as well as engine construction. As result, several solutions for converting reciprocating motion of a piston into rotational motion of a crankshaft have been invented [1-3].

One of these kinematic mechanisms is presented in the paper. The main feature of this mechanism is a rocker, which joins two rods: first one placed between the piston and the rocker, the second one - between the rocker and the crankshaft, respectively. In past (1950s and 1960s), an engine equipped with a rocker and two rods for the each piston was the 2-stroke diesel Commer TS3 engine built by Tilling-Stevens in the Rootes Group [3,4]. The each cylinder contained two pistons placed horizontally facing head-to-head and moved in opposition to each other (Fig. 1). It was launched into series production and fitted in trucks.

\section{Rocker engine description}

Concept of applying the rocker as the element for combining combustion forces from 4 pistons into a single crank of the crankshaft was the main idea of this design (Fig. 2). Hence, the mechanism examined in the paper is novel work and is under intellectual protection. Unlike the 
two-stroke Commer engine, the rocker engine presented in the paper is four-stroke one. The mechanism provides possibilities of obtaining various mean piston speeds at constant crankshaft rotational speed because the piston stroke is independent from the crank length. Additionally, the mechanism provides possibility of change in compression ratio. The conception is similar to solution proposed by Rychter and Teodorczyk [5,6]. Their mechanism called the VR/VL uses variable crank to rod length ratio to change the compression ratio outside the engine.

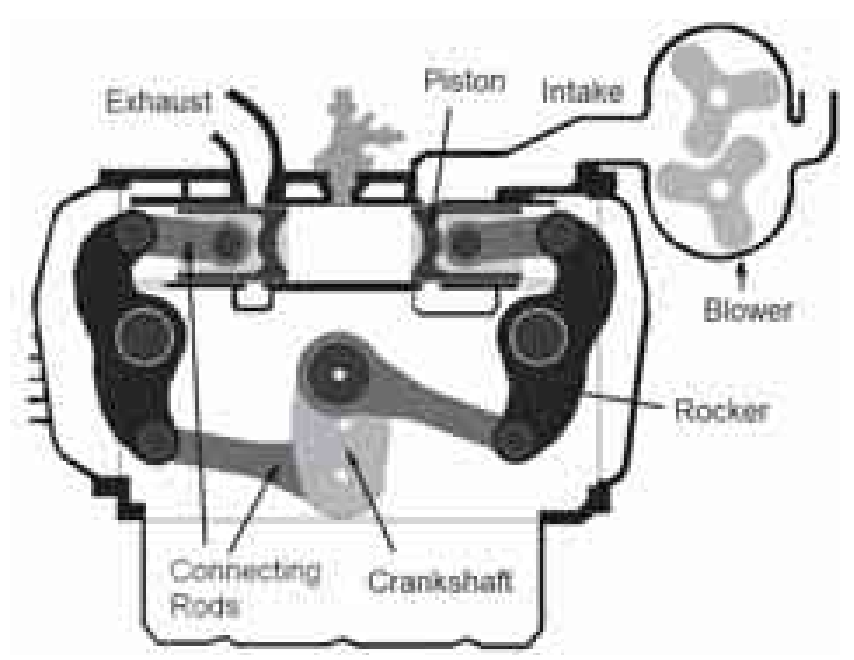

Fig. 1. Kinematic linkage in the rocker Commer engine

As depicted in the Fig. 2 the rocker in this conception connects 4 pistons and transfers motion with aid of the main connecting rod into the crankshaft. Each of these two pins in the rocker arms is individually linked with two pistons. In further analysis, the rocker is equipped with four pins separately connecting each piston to the rocker as shown in the Fig. 3 and 4.

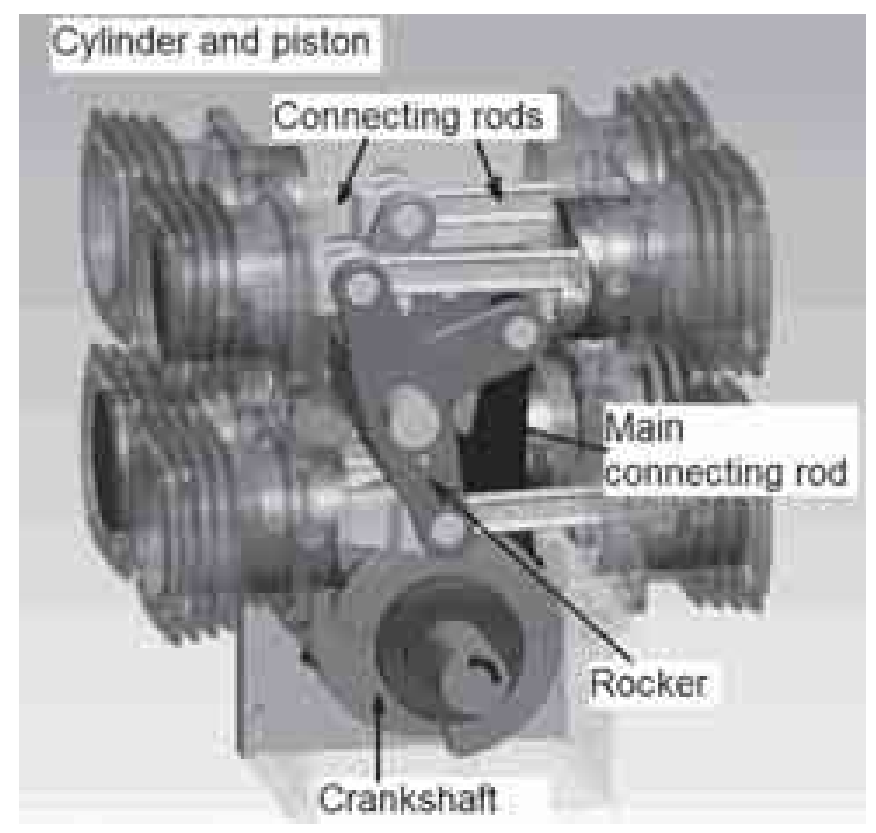

Fig. 2. Block of 8 cylinders of the rocker engine

\section{Numerical Analysis}

Numerical analysis concerns kinematics of the mechanism presented in the Fig. 3. As mentioned, the rocker consists of 4 pins - one for the each piston. 


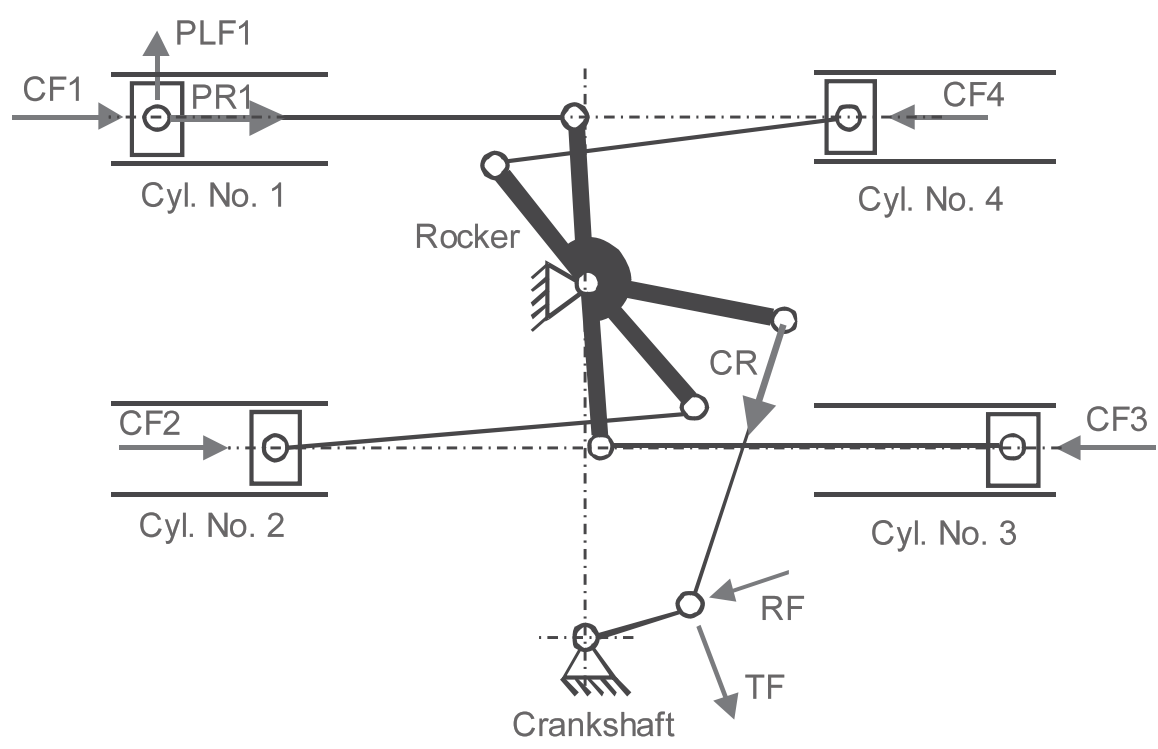

Fig. 3. Kinematic diagram with forces of the 4-cylinder rocker engine

The forces depicted in the Fig. 3 are defined as follows:

- CF1...CF4 - combustion forces,

- PR1 - piston-rod force,

- PLF1 - piston-liner force,

- $\mathrm{CR}$ - main connecting rod force,

- $\mathrm{RF}$ - radial force on the crank pin,

- $\mathrm{TF}$ - tangential force on the crank pin.

As the rocker is symmetrical with respect to its piston arms locations, both the piston No. 1 and the piston No. 3 move exactly at the same kinematics constrains. The same conclusion is valid for piston No. 2 and 4. Therefore, the model for analysis would be simplified to the form presented in the Fig. 4.

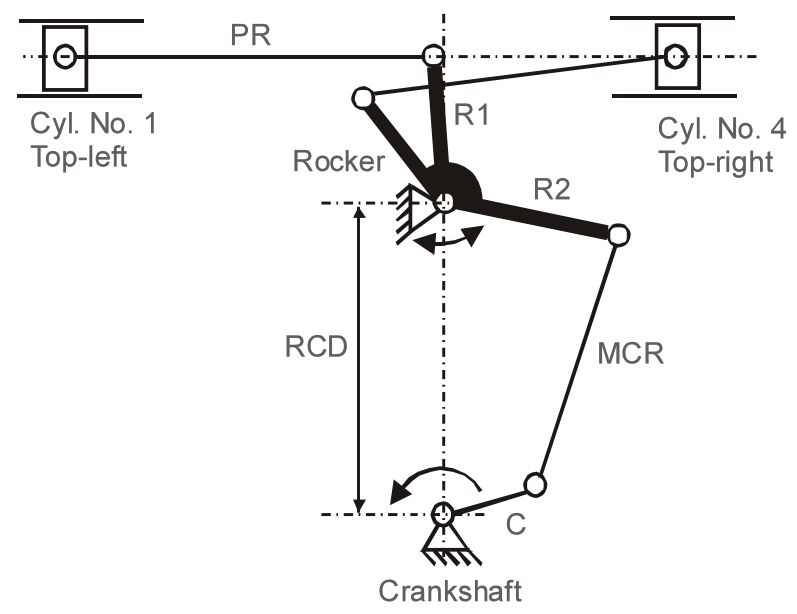

Fig. 4. Kinematic diagram of the 2-cylinder rocker engine

Dimensions introduced in the Fig. 4:

- RCD - Rocker to crankshaft distance,

- MCR - main connecting rod length,

- PR - piston rod length,

- C - crank length,

- R1, R2 - rocker arm length. 
The engine specification in details is shown in the Tab. 1. To determine combustion forces CF1 to $\mathrm{CF} 4$, the combustion pressure history (Fig. 5) was modelled with the conditions: real piston motion profile, assuming no heat transfer to walls, engine fuel: gasoline $\mathrm{C}_{8} \mathrm{H}_{15}$ and spark timing of 10 CA deg BTDC.

Tab. 1. Rocker engine specifications

\begin{tabular}{lll}
\hline Rocker engine specifications & & \\
\hline Bore & $\mathrm{D}(\mathrm{mm})$ & 82 \\
\hline Stroke & $\mathrm{L}(\mathrm{mm})$ & 69 \\
\hline Compression ratio & $\mathrm{CR}(-)$ & 10 \\
\hline Cylinder displacement & $\mathrm{Vs}(\mathrm{ccm})$ & 364.5 \\
\hline Rotational speed & $\mathrm{n}(\mathrm{rpm})$ & 1200 \\
\hline Firing order & - & $1-2-3-4$ \\
\hline Rocker to crankshaft distance & $\mathrm{RCD}(\mathrm{mm})$ & 101.7 \\
\hline Crank length & $\mathrm{C}(\mathrm{mm})$ & 35 \\
\hline Rocker arms R1=R2 & $\mathrm{R} 1, \mathrm{R} 2(\mathrm{~mm})$ & 65 \\
\hline Piston rod length & $\mathrm{PR}(\mathrm{mm})$ & 110 \\
\hline Main connecting rod length & $\mathrm{MCR}(\mathrm{mm})$ & 85.7 \\
\hline
\end{tabular}

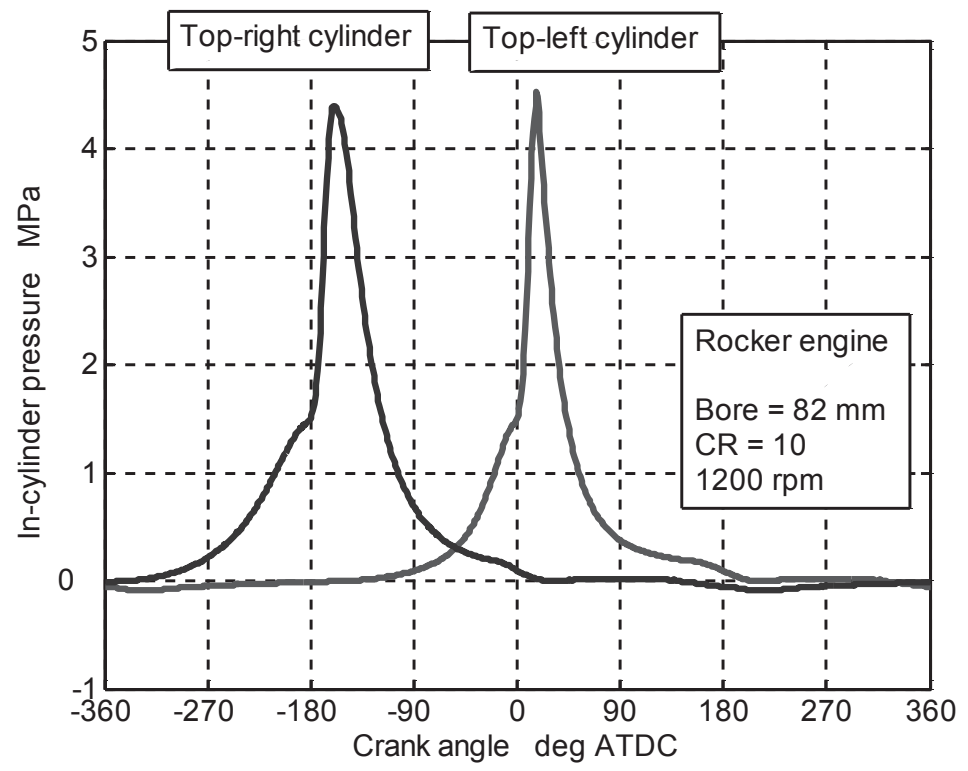

Fig. 5. Modelled combustion pressure in the 2-cylinder rocker engine

Next, tangential force acting on the crank pin was determined. This force corresponds to torque generated on the crankshaft. The entire tangential force generated by 4 cylinders is shown in the Fig. 6. As seen, there are two different peaks for this force coming from different cylinders. The higher peaks come from the cylinders 1 and 3. Additionally, the radial force is plotted. On the contrary to the previous remark, higher peaks in the radial force come from the cylinders No. 2 and 4 , that is obvious if someone consider that peaks in the resultant force transferred to the crank pin from the main connecting rod should equal each other for these 4 cylinders.

Important advantage of the rocker engine is relatively low frictional losses due to marginal transverse force acting by the piston on the cylinder liner side surface. As plotted in the Fig. 7 the peak in this force is almost 8 times lower than the peak in this force appearing in the classical engine. 


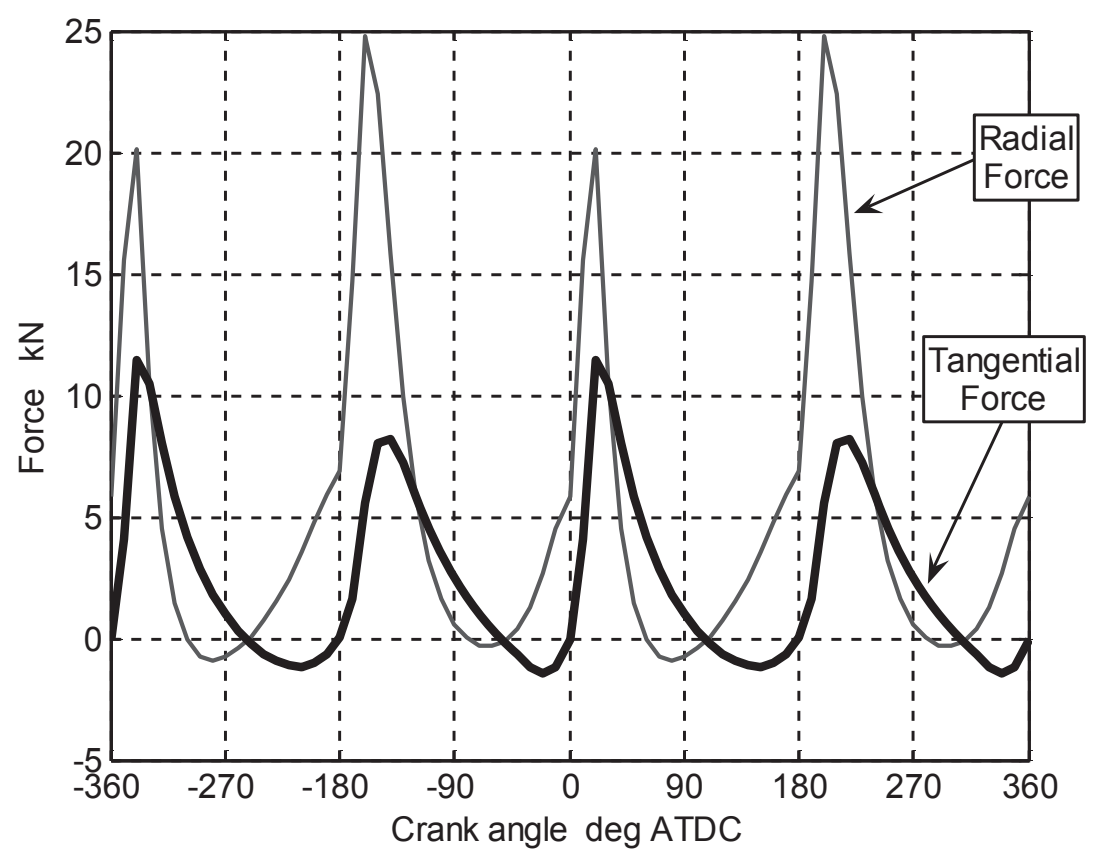

Fig. 6. Tangential and radial force in the crank pin of the 4-cylinder rocker engine

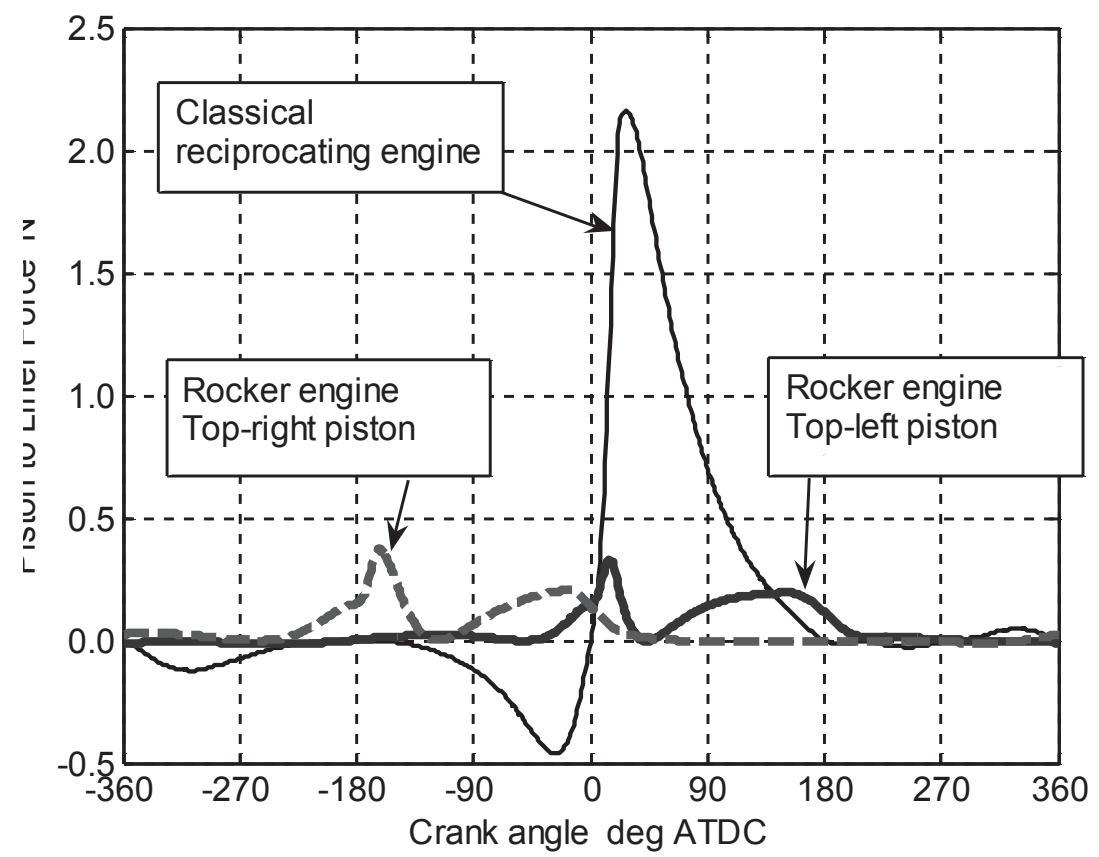

Fig. 7. Piston force acting on the liner-comparison between the rocker engine and the conventional one

Next significant difference between the classical engine and the rocker one is the piston motion profile vs. crank angle. As far as plenty of independent construction parameters are concerned there is potential to design various profiles of piston motion in the rocker engine. From thermodynamic point of view, it would be interesting to obtain fast motion of the piston from its TDC during the expansion stroke. It should contribute to remarkable drop in the combustion temperature, hence it should reduce heat transfer to walls and finally reduce thermal losses to the engine cooling system. Thus, higher in-cylinder gas internal energy should generate higher engine work. As depicted in Fig. 8 the top-left piston moves faster during expansion stroke. For instance, at crank angle of $45 \mathrm{CA}$ deg ATDC, the top-left piston is in distance of $18 \mathrm{~mm}$ from its TDC, while the piston of the conventional engine is located significantly closer $(12 \mathrm{~mm})$ to its TDC. 


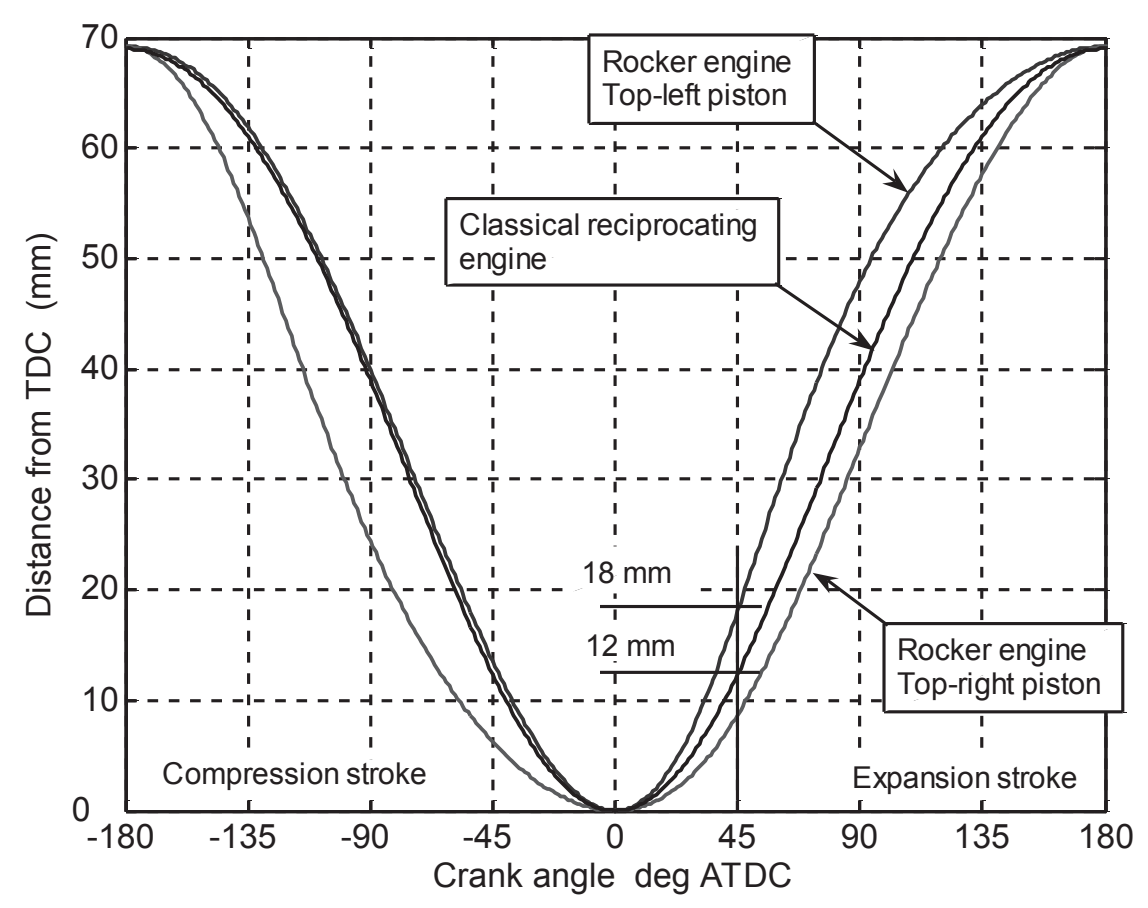

Fig. 8. Piston motion profile

\section{Advantages and disadvantages}

Tab. 2 Advantages and disadvantages

\begin{tabular}{|c|c|c|}
\hline & Advantages & Comments \\
\hline 1. & $\begin{array}{l}\text { Possibility of } \\
\text { changing the } \\
\text { piston stroke } \\
\text { without crankshaft } \\
\text { modifications }\end{array}$ & $\begin{array}{l}\text { At phase the designing works, it gives potential to set the piston stroke } \\
\text { independently from the length of the crank, hence various mean piston speed } \\
\text { can be achieved at fixed rotational speed of the crankshaft. Furthermore, } \\
\text { compression ratio of the engine can be flexibly changed during engine work. } \\
\text { As far as lengthening the piston stroke is available, the cylinder bore can be } \\
\text { decreased to keep the engine displacement not changed. Hence, optimization } \\
\text { of the total surface of the in-cylinder combustion chamber responsible for } \\
\text { heat transfer to walls is available. }\end{array}$ \\
\hline 2. & $\begin{array}{l}\text { Profile of piston } \\
\text { motion }\end{array}$ & $\begin{array}{l}\text { There is possibility of optimizing the piston motion profile to get significantly } \\
\text { faster piston receding from its TDC. It leads to faster expansion approaching } \\
\text { it to the adiabatic process. }\end{array}$ \\
\hline 3. & $\begin{array}{l}\text { Lower piston to } \\
\text { liner force }\end{array}$ & $\begin{array}{l}\text { Maximal angle between piston motion direction and the piston rod } \\
\text { longitudinal axis is marginal that leads to remarkably lower transverse force } \\
\text { from the piston acting on the cylinder liner. Lower force causes lower } \\
\text { frictional losses. As presented, this force can be } 8 \text { times lower than the force } \\
\text { appearing in the conventional reciprocating mechanism. Thus, construction of } \\
\text { a marine engine can be simplified. }\end{array}$ \\
\hline & $\begin{array}{l}\text { Short engine } \\
\text { crankshaft }\end{array}$ & $\begin{array}{l}\text { It increases rigidity of the crankshaft and in this way it contributes to increase } \\
\text { in free vibration frequency of the crankshaft. Hence, it would decrease } \\
\text { crankshaft torsional stress, particularly in case the engine consists of } 4 \text { pistons } \\
\text { and one crank. }\end{array}$ \\
\hline & Compactness & $\begin{array}{l}\text { The compactness of the engine with } 2 \text { rockers and } 8 \text { cylinders is found to be } \\
\text { better than the } 8 \text { V-type engine. }\end{array}$ \\
\hline \multicolumn{3}{|c|}{ Disadvantages } \\
\hline \multicolumn{3}{|c|}{ 1. Higher inertial forces } \\
\hline
\end{tabular}




\section{Conclusions}

As far as there are lots of engine construction parameters, which can be independently set, the rocker engine has bigger potential for improvement in its thermodynamic cycle in comparison to the conventional reciprocating engine.

Among others, the crucial feature is insignificant transverse force from the piston to the liner that reduces frictional losses to marginal numbers.

The other important feature is the engine work cycle can be improved by approaching it to the adiabatic process that reduces heat losses to an engine cooling system and provides energy to be converted to engine useful work.

With respect to higher inertial forces the primary application for the rocker engine is a power generating set or a marine engine working at medium or low rotational speed of less than 1500 rpm.

The low-speed engine characterizes itself with relatively high stroke to bore ratio to maintain optimal mean piston speed. Thus, it additionally promotes increase of the piston stroke to obtain smaller combustion chamber surface, so, to reduce thermal losses to a cooling system.

\section{References}

[1] Cichy, M, Konaszewski, S., Modelowanie układów mechanicznych metoda grafów wiązań na przykładzie mechanizmu korbowego, Journal of KONES, Vol. 7, pp. 77-82, 2000.

[2] Ciesiołkiewicz, A., Mężyk, P., Double Pistons Internal Combustion Engine, Journal of KONES, Vol. 1-2, pp. 56-64, 2002.

[3] http://www.pattakon.com/patop/CommerTS.gif.

[4] http://www.oldengine.org/members/diesel/Rootes-ListerTS3/TS3.htm.

[5] Rychter, T. J., Teodorczyk, A., Bruno Bossio, R., Naso, V., Thermodynamic Analysis of a Variable-Cycle IC Piston Engine, SAE, Paper No. 859297, 1985.

[6] Rychter, T. J., Teodorczyk, A., VR/LE Engine with Variable R/L during a Single Cycle, SAE Transactions, Paper No. 850206, pp. 2105-2123, 1985. 